\title{
Quantification of electrosurgery-related critical events during laparoscopic cholecystectomy - a prospective experimental study among surgical novices
}

\author{
Jens Rolinger ${ }^{1,2, *}$ (D), Nils Model $^{2,3}$ (D), Kai Jansen ${ }^{1,2}$, Madeleine Knöll ${ }^{4}$, Patrick Beyersdorffer ${ }^{2,5}$ (1), \\ Wolfgang Kunert ${ }^{2}$ (D), Steffen $\mathrm{Axt}^{2}$, Andreas Kirschniak ${ }^{1,2,{ }^{*}}$ (D), and Peter Wilhelm ${ }^{1,2}$ (D) \\ ${ }^{1}$ Department of Visceral Surgery, Maria Hilf Hospital Mönchengladbach, 41063 Mönchengladbach, Germany \\ ${ }^{2}$ Department of Surgery and Transplantation, Tübingen University Hospital, 72076 Tübingen, Germany \\ ${ }^{3}$ Faculty of Science, Department of Computer Science, Tübingen University, 72074 Tübingen, Germany \\ ${ }^{4}$ Department of Nephrology, Düsseldorf University Hospital, 40225 Düsseldorf, Germany \\ ${ }^{5}$ Faculty of Computer Science, Reutlingen University, 72762 Reutlingen, Germany
}

Received 30 December 2021, Accepted 4 January 2022

\begin{abstract}
Uncontrolled movement of instruments in laparoscopic surgery can lead to inadvertent tissue damage, particularly when the dissecting or electrosurgical instrument is located outside the field of view of the laparoscopic camera. The incidence and relevance of such events are currently unknown. The present work aims to identify and quantify potentially dangerous situations using the example of laparoscopic cholecystectomy (LC). Twenty-four final year medical students were prompted to each perform four consecutive LC attempts on a well-established box trainer in a surgical training environment following a standardized protocol in a porcine model. The following situation was defined as a critical event (CE): the dissecting instrument was inadvertently located outside the laparoscopic camera's field of view. Simultaneous activation of the electrosurgical unit was defined as a highly critical event (hCE). Primary endpoint was the incidence of CEs. While performing $96 \mathrm{LCs}, 2895 \mathrm{CEs}$ were observed. Of these, 1059 (36.6\%) were hCEs. The median number of CEs per LC was 20.5 (range: 1-125; IQR: 33) and the median number of hCEs per LC was 8.0 (range: 0-54, IQR: 10). Mean total operation time was 34.7 min (range: $15.6-62.5 \mathrm{~min}$, IQR: $14.3 \mathrm{~min}$ ). Our study demonstrates the significance of CEs as a potential risk factor for collateral damage during LC. Further studies are needed to investigate the occurrence of $\mathrm{CE}$ in clinical practice, not just for laparoscopic cholecystectomy but also for other procedures. Systematic training of future surgeons as well as technical solutions address this safety issue.
\end{abstract}

Keywords: Surgical training, Laparoscopic surgery, Inadvertent injury, Electrosurgery, Patient safety, Prospective experimental study

\section{Introduction}

Despite its undeniable advantages [1], the introduction of minimally invasive surgical techniques has increased the complexity of surgical procedures because of the transmission of visual information via laparoscopic imaging. Laparoscopic instruments are not always located within the surgeon's direct field of view and yet need to be steered in a three-dimensional space via the presented digital image section [2]. Inappropriate camera settings and uncontrolled movement of the instruments can lead to inadvertent injury of adjacent structures [3, 4], especially when the dissecting instrument is actuated outside the field of view of the laparoscopic camera [5].

\footnotetext{
*Corresponding authors: jens.rolinger@mariahilf.de; andreas.kirschniak@mariahilf.de
}

In Figure 1a the laparoscopic instrument is located at the right edge of the image section. However, the pointed and hot tip of the instrument is not visible to the surgical team. Zooming out reveals the potential risk of injury to neighboring structures in this context (Fig. 1b). In addition, the dissecting instrument (e.g., the monopolar hook) frequently has to exert a certain tensile stress on the target tissue during surgical preparation. Slipping off or tearing tissue can cause sudden and uncontrolled flinging movements of the effector outside the laparoscopic field of view while the electrosurgical device is still activated.

Injuries to neighboring organs (e.g., small intestine, vascular structures) account for serious complications with long-term adverse effects, particularly on quality of life, even after successful revision [6, 7]. These lesions often go unnoticed during the initial procedure and are revealed 

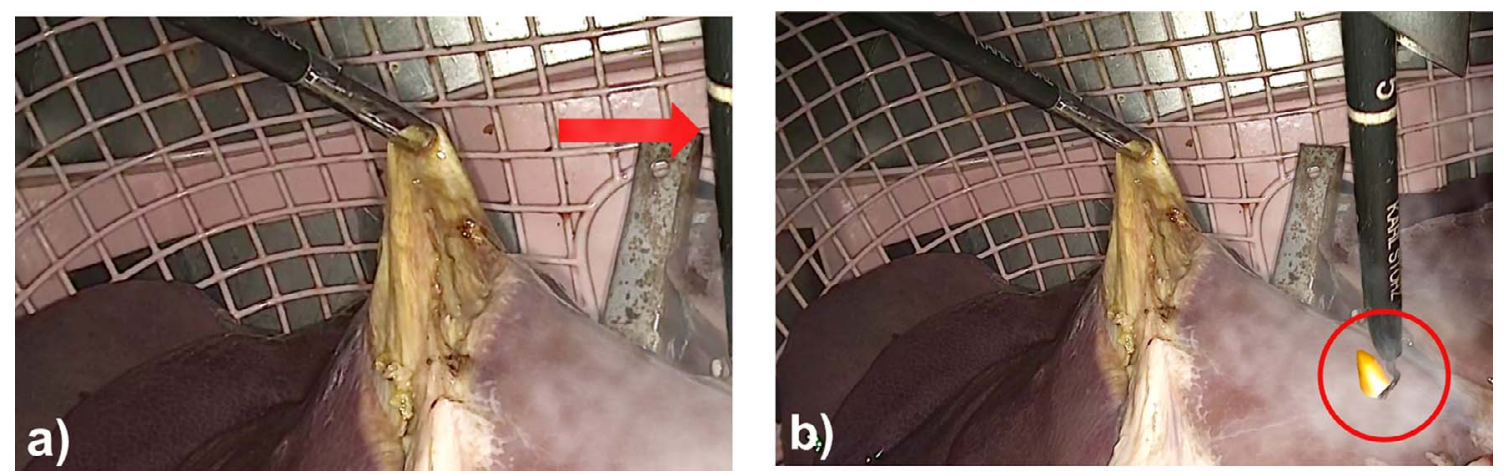

Figure 1. Electrosurgical instrument (red arrow) located near the right edge of the laparoscopic image section (a) and overview perspective (b) with visible instrument tip (potential electrical damage, red circle).

later in the clinical course by a worsening general condition of the patient $[6,8]$. The European Association of Endoscopic Surgeons (EAES) has recently published a classification of intraoperative adverse events (AE) in laparoscopic surgery to help enhancing the consistency in future reporting [9].

Studies on the impact of residents' experiences on the surgical outcome show inconsistent results regarding the occurrence of $\mathrm{AE}$ and postoperative morbidity [10-12]. While the chance for immediate intervention by an experienced surgeon during in-OR training of surgical novices is usually given, this is rarely the case in laparoscopy with the senior surgeon guiding the camera and being spatially separated from the instrument's effector. To our knowledge there are no studies addressing the correlation of surgical novices and the occurrence of situations that can possibly cause AEs. We defined situations when the dissecting instrument was unintentionally located outside the laparoscopic camera's field of view to be potential causes for AEs and introduced the term "critical event" $(\mathrm{CE})$.

The aim of the present study was the quantitative and qualitative investigation of CEs situations during laparoscopic surgery. For this purpose, laparoscopic cholecystectomy (LC) in a standardized training environment was used as an example. To the best of our knowledge, a comparable analysis is not yet available in the literature.

\section{Materials and methods}

\section{Study design}

For this prospective experimental study, 24 final-year medical students were recruited. Inclusion criteria were no practical experience in laparoscopic surgery and voluntary written consent to participate in the study. The subjects were prompted to perform four consecutive LCs at the surgical training center in Tübingen. The operations were performed on a well-established box trainer using porcine livers [13] following a standardized surgical protocol (Tab. 1) [14]. The study protocol was approved by the
Table 1. Nodal points of a standardized laparoscopic cholecystectomy at the surgical training center in Tübingen; substeps in italics were excluded due to the design features of the box trainer and to increase the efficiency of the study process.

1. Inserting the trocars under visual control

2. Retracting the liver

3. Performing the V-shaped preparation close to the gallbladder

4. Achieving the "Critical View of Safety"

5. Clipping and dissecting the cystic duct

6. Clipping and dissecting the cystic artery

7. Removing the gallbladder from the gallbladder bed

8. Retrieving the gallbladder using a retrieval bag

9. Ensuring hemostasis and checking the applied clips

10. Retracting the trocars under visual control and wound closure

Institutional Ethics Review board (Project Number 272/2017BO2).

Each session started with an oral presentation explaining the procedure to be undertaken. To reduce external influencing factors, the laparoscopic camera was mounted on a mechanical support arm during surgery. Its position could be autonomously manipulated by the subjects, as necessary. Two members of the working group were present but gave assistance only on explicit request of the test subjects and did not actively interact.

After completion of the study, the video and audio material was evaluated by two separate members of the working group. The analysis was completed using the VLC Media Player (VideoLAN, Paris, France) in version 2.0.

In the present study, the following condition was defined as a CE: the dissecting instrument (in our case the coagulation and dissection electrode) is inadvertently located outside the field of view of the laparoscopic camera. Simultaneous activation of the electrosurgical unit was defined as a highly critical event (hCE). In contrast, intentional replacement of the dissecting instrument or its positioning within a trocar was not assessed. The surgical scenario was classified as controllable when there are pointed or hot instruments in the abdomen and these are simultaneously captured by the laparoscopic image section. 


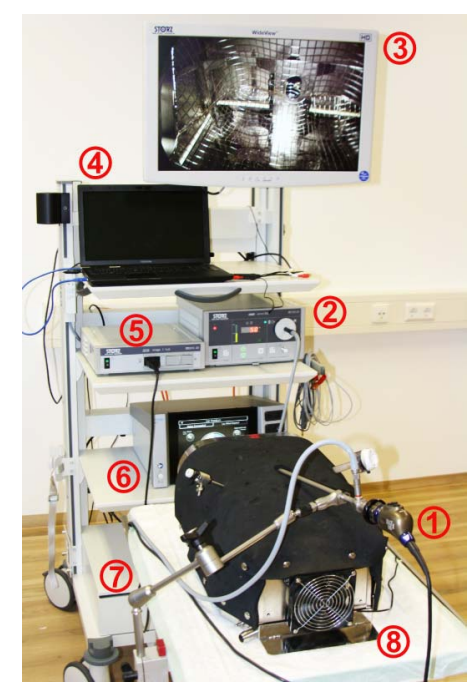

Figure 2. Experiment setup at the surgical training center in Tübingen with (1) endocam with attached laparoscope, (2) light source, (3) LCD monitor, (4) computer for media recording and processing, (5) camera control unit, (6) electrosurgical control unit, (7) mechanical support arm, (8) box trainer including ventilation system.

\section{Study endpoints}

The primary study endpoint was to quantify the number of CEs occurring during laparoscopic cholecystectomy in a standardized training environment. The corresponding number of critical hCEs was defined as a secondary endpoint.

\section{Equipment}

Standard equipment for laparoscopic surgery (Karl Storz SE \& Co. KG, Tuttlingen, Germany) was used (Fig. 2): light source Xenon $300 \mathrm{SCB}$, Hopkins ${ }^{\circledR}$ forwardoblique laparoscope $(10 \mathrm{~mm}$ diameter, $31 \mathrm{~cm}$ working length, $30^{\circ}$ viewing direction), endocam IMAGE ${ }^{\mathrm{TM}}$ (full HD), LCD monitor SC-WU26 (full HD, 26 inches diagonal) as well as standard laparoscopic instruments including CLICKline ${ }^{\circledR}$ grasping forceps $33310 \mathrm{ON}$ (5 mm diameter, working length $36 \mathrm{~cm}$ ), and Cadiere coagulation and dissection electrode $26775 \mathrm{C}$ (5 mm diameter, working length $36 \mathrm{~cm}$ ).

The image data were captured with the video grabber Magewell ${ }^{\circledR}$ XI100D USB 3.0 - HDMI video capture box (Nanjing Magewell Electronics Co., Ltd., Nanjing, China; 16:9 aspect ratio, full $\mathrm{HD}, 60$ frames per second, RGB color model). To register activation of the electrosurgical unit during the surgical procedure, the microphone ZM-MIC1 (Zalman Tech Co., Ltd., Anyang, South Korea) was used to record the audible warning tone. The recording and processing of both the audio and video signal were realized with a customized application based on the Microsoft Expression Encoder 4 Software Development Kit (Microsoft Corporation, Redmond, WA, USA).

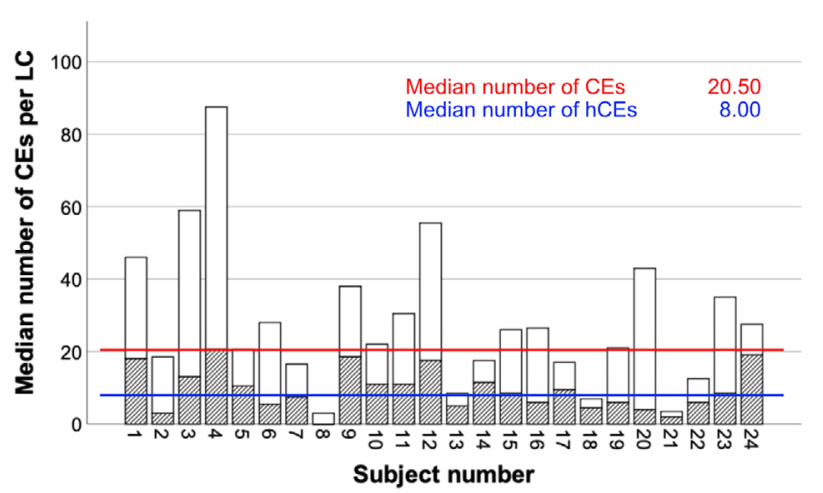

Figure 3. Median number of CEs per LC (white part of column) and proportionally the median number of hCEs per LC (hatched part of column), $n=24$ subjects with four LCs each (total 96 LCs with four LCs per column).

\section{Statistical analysis}

For statistical analysis, SPSS ${ }^{\circledR}$ version 25 (International Business Machines Corporation, Armonk, NY, USA) software was used. The median values and the interquartile range (IQR) were calculated. The obtained data were analyzed for normal distribution using the Shapiro-Wilk $W$ test. A Friedman test was run to determine if there were differences between the four rounds of the trial in terms of study endpoints and operating time. $p$ values $<0.05$ were considered significant.

\section{Results}

In all LCs ( $n=24$ subjects with 4 LCs each, giving a total of 96 LCs) performed, 2895 CEs were observed. Of these, 1059 were hCEs. This corresponds to an adverse events rate of $36.6 \%$. The median number of CEs per LC was 20.50 (range $=1-125 ; \mathrm{IQR}=33$ ) and the median number of hCEs per LC was 8.00 (0-54; IQR 10) (Fig. 3). The median number of CEs per minute was 0.68 (0.044.32; IQR 0.81) and the median number of hCEs per minute was 0.25 (0.00-1.47; IQR 0.31) (Fig. 4).

CRP concentration decreased from pre- $(\mathrm{Mdn}=4.10)$, to midway $(\mathrm{Mdn}=3.85)$, to post-intervention $(\mathrm{Mdn}=$ $3.55)$, but the differences were not statistically significant, $\chi^{2}(2)=1.168, p=0.542$.

Although the number of CE per LC (Fig. 5) increased over the course of the different attempts (median attempt $1=15.0 ; 2=18.5 ; 3=20.5 ; 4=38.0$ ), the Friedman test failed to demonstrate a statistically significant difference $(p=0.541)$. This also applies to the number of hCE (Fig. 6) (median attempt $1=5.0 ; 2=8.0 ; 3=9.5$; $4=9.0)(p=0.731)$.

Median operating time per LC was $34.67 \mathrm{~min}$ $($ range $=15.62-62.55 \mathrm{~min} ; \mathrm{IQR}=14.32 \mathrm{~min})$. Correlation analysis using Bravais-Pearson showed a positive correlation between the number of CEs per LC and surgery time $(r=0.397 ; p<0.001 ; n=96)$. According to Cohen [15], this was a medium effect. The median operating time initially 


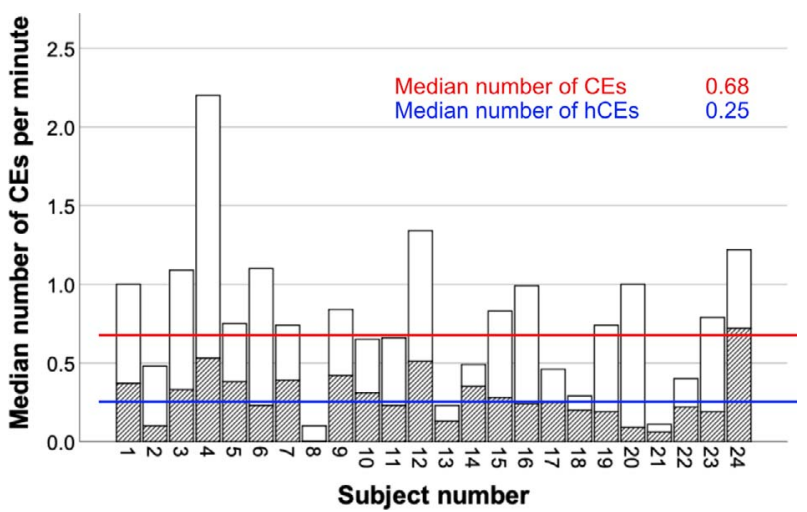

Figure 4. Median number of CEs per minute (white part of column) and proportionally the median number of hCEs per minute (hatched part of column), $n=24$ subjects with four LCs each (total 96 LCs with four LCs per column)

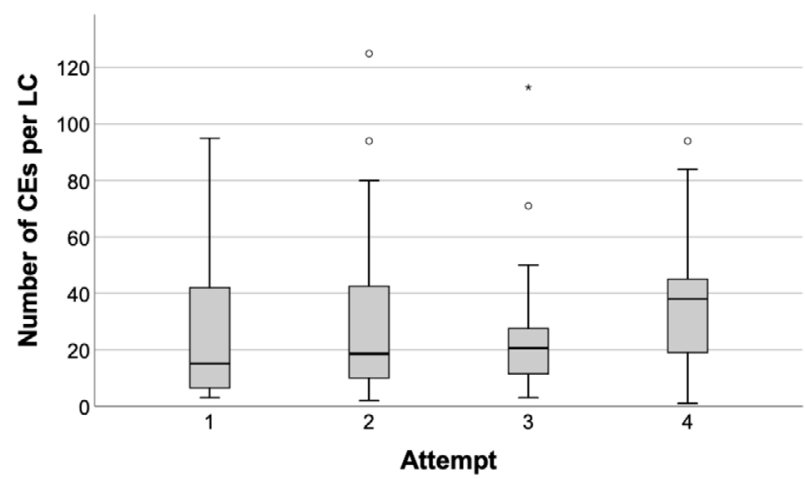

Figure 5. Number of CEs per LC in the total population broken down into attempts $1-4$, per box plot $n=24$ subjects with one LC per attempt (total 96 LCs with 24 LCs per boxplot).

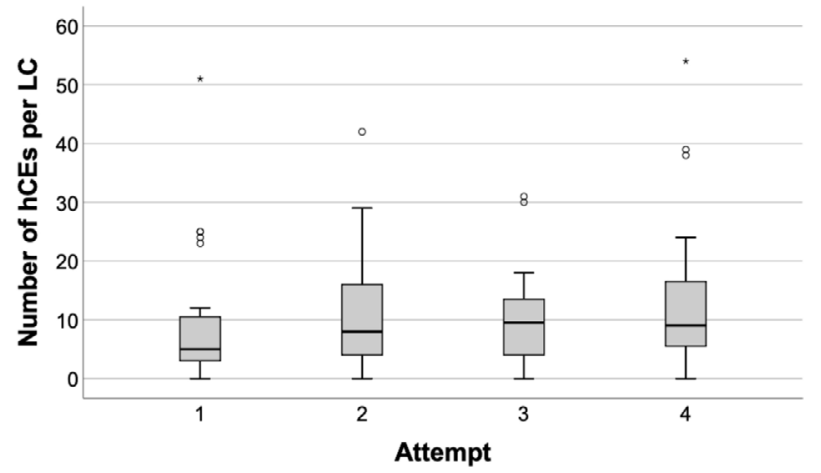

Figure 6. Number of hCEs per LC in the total population broken down into attempts $1-4$, per box plot $n=24$ subjects with one LC per attempt (total 96 LCs with 24 LCs per boxplot).

decreased from the first (median $=37.29 \mathrm{~min}$ ) to the second (34.69 $\mathrm{min})$ to the third attempt (30.56 $\mathrm{min})$ and then increased again (35.91 $\mathrm{min}$ for the fourth attempt), but the differences were not statistically significant according to the Friedman test $(p=0.092)$.

The variables CEs (per LC as well as per minute) and critical hCEs (per LC as well as per minute) were not normally distributed (each $p<0.001$ ). Data distribution was clearly right skewed. With regard to the operating time, the data set was normally distributed $(p=0.226)$. With regard to exploratory data analysis, the median and the IQR were used for all variables mentioned.

\section{Discussion}

The rapidly advancing adoption of minimally invasive surgical techniques is confronted with a considerable number of iatrogenic injuries with potentially severe consequences for patients. Particularly with regard to mechanically and thermally caused injuries to adjacent tissue structures in the context of modern electrosurgery, there are no comprehensive solutions available so far [3, 4].

The incidence of iatrogenic injuries during laparoscopic interventions is stated to be up to $0.5 \%$ of all cases $[6,8,16-21]$. Significantly higher incidence rates are described in connection with more complex laparoscopic procedures [22, 23]. Some authors even suspect a significant number of unreported cases [6, 24]. Statements regarding associated morbidity and mortality need to be interpreted with caution in view of the inconsistent recording in the various available studies $[6,8,16]$. However, the mortality rate is reported to be up to $3 \%$ and is decisively influenced by the early recognition of inadvertent tissue trauma, preferably during the primary intervention $[6,8]$.

Regarding the injury mechanism, access-related lesions are distinguished from inadvertent tissue damage during surgical dissection $[3,4,25]$. The latter account for $50-$ $60 \%$ of the complications $[8,17,25]$, with thermal lesions playing an important role in this context [26-30]. Electrosurgical instruments and other new hemostatic energy devices have become an integral part of modern medicine. Not only in the field of surgery, but also in areas such as endoscopy or interventional radiology, such devices are used throughout the world and across all surgical disciplines due to their evident benefits [31, 32].

Unintentional activation of the instrument outside the laparoscopic image section can lead to considerable thermal damage to adjacent tissue structures through direct contact or indirect energy coupling $[27,28,30,33]$. In this connection, aspects such as residual heat and cooling times of electrosurgical instruments should not be underestimated [34]. This aspect is especially concerning as such AEs are often considered to be preventable [35]. With growing awareness in the surgical community as well as the ongoing development of technological capabilities, the aspect of patient safety is acquiring increasing topical relevance [36].

The results of the present study support the working hypothesis that a significant number of (h)CEs can occur during standard laparoscopic procedures, such as cholecystectomy, in a standardized training environment. At first glance, these results seem excessively high considering the 
possibly serious consequences for the patients concerned. It should be noted that the examined CEs represent only a potential risk factor for lesions to adjacent anatomical structures. Considering the incidence rates for inadvertent injuries in laparoscopy known from the scientific literature, it is obvious that not every CE leads to a clinically relevant complication $[6,8,16-21]$. Yet, we state that beginners in laparoscopy potentially initiate hCEs that cannot be compensated by a by standing experienced surgeon.

The proposed approach involves some limitations. First, only medical students without prior laparoscopic experience participated in the study. This is reflected in the wide standard deviations of the CEs. Therefore, the wider application of this study to experienced laparoscopic surgeries may be limited. LC remains a complex procedure for this target group. Laparoscopic experts can be expected to cause a smaller number of CEs and hCEs. Moreover, the increasing number of CEs during the four rounds could be an expression of cumulative fatigue and stress. This aspect presents high congruence with our long experience at one of Europe's first surgical training centers [37]. Future studies might extend the pause times of the test persons between their experiments. Probably four repetitions are not enough, and the learning curve is too steep to produce an apparent learning effect.

However, LC is of great value especially in early visceral surgery training $[38,39]$. Novices without prior experience in laparoscopic surgery provide a representative cohort of junior residents who can benefit from simulated surgical training. Medical students, therefore, can be considered to be on the same level of laparoscopic experience as surgical novices at the beginning of their career. In view of the purpose of the present study, a reasonably realistic experiment setup can be assumed [40]. This is also reflected in the evaluations of comparable training environments of other working groups [41, 42]. Further research is needed to investigate the occurrence of CEs in the setting of a real operating room, not only for laparoscopic cholecystectomy but also for other procedures.

The operating theatre is a complex working environment. The reasons for the occurrence of CEs are therefore to be found not only in careless handling of the dissecting instrument, but also in poor camera guidance and lack of communication. The impact of proper camera guidance on the course and success of a surgical procedure has already been demonstrated in previous studies [43, 44]. This also applies to communication and coordination within the surgical team $[45,46]$. Under challenging circumstances, the risk of injuring adjacent structures increases and, consequently, adherence to established safety strategies is of utmost importance [36, 47, 48]. To ensure patient safety and avoid CE during surgery, thorough and systematic training of junior surgeons is also essential [49-52]. The value of realistic training concepts executed on suitable simulators outside the day-to-day environment of the operating room has been proven in various studies [53-57].

The advancing digitalization and integration of different interfaces by means of modern information and communication technologies covers all areas of medicine, including surgery in particular. The immense potential of surgical data science aims to provide additional information and assistance functions during a surgical procedure. MaierHein et al. identified context-sensitive assistance systems and surgical training as key applications for this future sector [36]. In this respect, the automated, objective evaluation of surgical-technical performance and skills develops into an important field of application. It enables the documentation of training success as well as the analysis of personal and structural deficits with the intention of specifically addressing them [58]. The collected data were integrated into the automated, objective evaluation of surgical skills [59].

Apart from the training aspect, especially with regard to thermally caused damage to neighboring organs in the context of modern energy devices, technical solutions are appreciated [60-62]. Optimal technical support of the surgeon is not accompanied by extended duration of surgery, a tedious learning curve or significantly increasing costs $[61,63]$. Whenever a pointed or hot instrument tip leaves the laparoscopic camera's field of view, this should be automatically detected and reported to the surgeon in audiovisual form. Integrated operating room systems could even take measures to prevent energy application at the wrong time. Modern information technologies, such as artificial neural networks (ANN) - a branch of artificial intelligence - can be used to integrate and evaluate the image data acquired during the operation. Previously published works have described different methods that use ANN to analyze complex surgical image data with various objectives. These include the assessment of surgical skills in the context of surgical training [59] or workflow analysis in the operating theater [64].

In conclusion, the results of the present study emphasize the relevance of CEs as potentially dangerous situations during laparoscopic surgery. These findings have potential implications for the development of context-sensitive assistance systems as well as the objective evaluation of surgical skills.

\section{List of abbreviations}

AE Adverse event

ANN Artificial neural networks

CE Critical event

EAES European Association of Endoscopic Surgeons

hCE Highly critical event

IQR Interquartile range

LC Laparoscopic cholecystectomy

RGB Red-green-blue (additive color space)

USA United States of America

\section{Author contributions}

All authors contributed to study conception and design. The development and configuration of the technical setup as well as the used software were performed by Nils Model 
and Patrick Beyersdorffer according to the ideas and specifications of Jens Rolinger. Material preparation and data collection were performed by Kai Jansen, Nils Model, Patrick Beyersdorffer, Steffen Axt, Peter Wilhelm and Jens Rolinger. The video and audio material was analyzed by Madeleine Knöll and Jens Rolinger. Wolfgang Kunert and Jens Rolinger performed the statistical evaluation of the data obtained. The first draft of the manuscript was written by Jens Rolinger and revised by Andreas Kirschniak and Peter Wilhelm. All authors commented on previous versions of the manuscript. All authors read and approved the final manuscript.

\section{Conflict of interest}

Jens Rolinger, Nils Model, Kai Jansen, Madeleine Knöll, Patrick Beyersdorffer, Wolfgang Kunert, Steffen Axt, Andreas Kirschniak and Peter Wilhelm have no conflicts of interests or financial ties to disclose.

\section{Ethics approval and consent}

The study protocol was approved by the institutional ethics review board. All probands gave written informed consent to participate in the study.

\section{Acknowledgments}

The abstract of the present work was presented as a poster at the 28th International Congress of the European Association for Endoscopic Surgery (EAES) Virtual Congress 23-26 June 2020.

\section{References}

1. Buia A, Stockhausen F, Hanisch E (2015), Laparoscopic surgery: a qualified systematic review. World J Methodol 5, 238-254. https://doi.org/10.5662/wjm.v5.i4.238.

2. Sorensen SM, Savran MM, Konge L, Bjerrum F (2016), Three-dimensional versus two-dimensional vision in laparoscopy: a systematic review. Surg Endosc 30, 11-23. https://doi.org/10.1007/s00464-015-4189-7.

3. Kaplan JR, Lee Z, Eun DD, Reese AC (2016), Complications of minimally invasive surgery and their management. Curr Urol Rep 17, 47. https://doi.org/10.1007/s11934-016-0602-6.

4. Sotelo RJ, Haese A, Machuca V, Medina L, Nunez L, Santinelli F, Hernandez A, Kural AR, Mottrie A, Giedelman C, Mirandolino M, Palmer K, Abaza R, Ghavamian R, Shalhav A, Moinzadeh A, Patel V, Stifelman M, Tuerk I, Canes D (2016), Safer surgery by learning from complications: a focus on robotic prostate surgery. Eur Urol 69, 334344. https://doi.org/10.1016/j.eururo.2015.08.060.

5. Kunert W, Land C, Braun M, Reichold J, Kirschniak A, Falch C (2020), The impact of guided instrument insertion during laparoscopy: a randomized study with novices in an optical box trainer. Surg Endosc 34, 787-795. https://doi. org/10.1007/s00464-019-06829-4.

6. Cassaro S (2015), Delayed manifestations of laparoscopic bowel injury. Am Surg 81, 478-482. https://doi.org/ $10.1177 / 000313481508100529$.
7. Machado NO (2016), Duodenal injury post laparoscopic cholecystectomy: incidence, mechanism, management and outcome. World J Gastrointest Surg 8, 335-344. https://doi. org/10.4240/wjgs.v8.i4.335.

8. Llarena NC, Shah AB, Milad MP (2015), Bowel injury in gynecologic laparoscopy: a systematic review. Obstet Gynecol 125, 1407-1417. https://doi.org/10.1097/AOG. 0000000000000855.

9. Francis NK, Curtis NJ, Conti JA, Foster JD, Bonjer HJ, Hanna GB (2018), EAES classification of intraoperative adverse events in laparoscopic surgery. Surg Endosc 32, 3822-3829. https://doi.org/10.1007/s00464-018-6108-1.

10. Wojcik BM, Lee JM, Peponis T, Amari N, Mendoza AE, Rosenthal MG, Saillant NN, Fagenholz PJ, King DR, Phitayakorn R, Velmahos G, Kaafarani HM (2018), Do not blame the resident: the impact of surgeon and surgical trainee experience on the occurrence of intraoperative adverse events (iAEs) in abdominal surgery. J Surg Educ 75, e156-e167. https://doi.org/10.1016/j.jsurg.2018.07.020.

11. Scarborough JE, Bennett KM, Pappas TN (2012), Defining the impact of resident participation on outcomes after appendectomy. Ann Surg 255, 577-582. https://doi.org/ 10.1097/SLA.0b013e3182468ed9.

12. Davis SS Jr, Husain FA, Lin E, Nandipati KC, Perez S, Sweeney JF (2013), Resident participation in index laparoscopic general surgical cases: impact of the learning environment on surgical outcomes. J Am Coll Surg 216, 96-104. https://doi.org/10.1016/j.jamcollsurg.2012.08.014.

13. Waseda M, Inaki N, Mailaender L, Buess GF (2005), An innovative trainer for surgical procedures using animal organs. Minim Invasive Ther Allied Technol 14, 262-266. https://doi.org/10.1080/13645700500273841.

14. Niwa UC, Axt S, Falch C, Muller S, Kreuzer JA, Nedela P, Kirschniak A (2013), Laparoscopic cholecystectomy as standardised teaching operation to treat symptomatic cholecystolithiasis. Zentralbl Chir 138, 141-142. https://doi.org/ $10.1055 / \mathrm{s}-0032-1328396$.

15. Cohen J (1988), Statistical power analysis for the behavioral sciences, 2nd edn., Routledge, New York. https://doi.org/ 10.4324/9780203771587.

16. Bishoff JT, Allaf ME, Kirkels W, Moore RG, Kavoussi LR, Schroder F (1999), Laparoscopic bowel injury: incidence and clinical presentation. J Urol 161, 887-890. https://doi.org/ 10.1016/s0022-5347(01)61797-x.

17. Magrina JF (2002), Complications of laparoscopic surgery. Clin Obstet Gynecol 45, 469-480. https://doi.org/10.1097/ 00003081-200206000-00018.

18. Jansen FW, Kolkman W, Bakkum EA, de Kroon CD, Trimbos-Kemper TC, Trimbos JB (2004), Complications of laparoscopy: an inquiry about closed- versus open-entry technique. Am J Obstet Gynecol 190, 634-638. https://doi. org/10.1016/j.ajog.2003.09.035.

19. Enochsson L, Thulin A, Osterberg J, Sandblom G, Persson G (2013), The Swedish Registry of Gallstone Surgery and Endoscopic Retrograde Cholangiopancreatography (GallRiks): a nationwide registry for quality assurance of gallstone surgery. JAMA Surg 148, 471-478. https://doi.org/ 10.1001/jamasurg.2013.1221.

20. Awolaran O, Gana T, Samuel N, Oaikhinan K (2017), Readmissions after laparoscopic cholecystectomy in a UK District General Hospital. Surg Endosc 31, 3534-3538. https://doi.org/10.1007/s00464-016-5380-1.

21. Kunzli BM, Spohnholz J, Braumann C, Shrikhande SV, Uhl W (2018), Clinical impact of iatrogenic small bowel perforation secondary to laparoscopic cholecystectomy: a singlecenter experience. Surg Laparosc Endosc Percutan Tech 28, 309-313. https://doi.org/10.1097/SLE.0000000000000561. 
22. O'Connor DB, Winter DC (2012), The role of laparoscopy in the management of acute small-bowel obstruction: a review of over 2,000 cases. Surg Endosc 26, 12-17. https://doi.org/ 10.1007/s00464-011-1885-9.

23. Sharma A, Khullar R, Soni V, Baijal M, Kapahi A, Najma K, Chowbey PK (2013), Iatrogenic enterotomy in laparoscopic ventral/incisional hernia repair: a single center experience of 2,346 patients over 17 years. Hernia 17, 581-587. https://doi. org/10.1007/s10029-013-1122-7.

24. Platz J, Hyman N (2012), Tracking intraoperative complications. J Am Coll Surg 215, 519-523. https://doi.org/ 10.1016/j.jamcollsurg.2012.06.001.

25. van der Voort M, Heijnsdijk EA, Gouma DJ (2004), Bowel injury as a complication of laparoscopy. Br J Surg 91, 12531258. https://doi.org/10.1002/bjs.4716.

26. Abu-Rafea B, Vilos GA, Al-Obeed O, AlSheikh A, Vilos AG, Al-Mandeel H (2011), Monopolar electrosurgery through single-port laparoscopy: a potential hidden hazard for bowel burns. J Minim Invasive Gynecol 18, 734-740. https://doi. org/10.1016/j.jmig.2011.07.015.

27. Sankaranarayanan G, Resapu RR, Jones DB, Schwaitzberg S, De S (2013), Common uses and cited complications of energy in surgery. Surg Endosc 27, 3056-3072. https://doi. org/10.1007/s00464-013-2823-9.

28. Overbey DM, Townsend NT, Chapman BC, Bennett DT, Foley LS, Rau AS, Yi JA, Jones EL, Stiegmann GV, Robinson TN (2015), Surgical energy-based device injuries and fatalities reported to the food and drug administration. J Am Coll Surg 221, 197-205. https://doi.org/10.1016/ j.jamcollsurg.2015.03.031.

29. Carvalho GL, Paquentin EM, Rao P (2016), Should highfrequency electrosurgery be discouraged during laparoscopic surgery? Surg Endosc 30, 401-403. https://doi.org/10.1007/ s00464-015-4536-8.

30. Martin KE, Moore CM, Tucker R, Fuchshuber P, Robinson $\mathrm{T}$ (2016), Quantifying inadvertent thermal bowel injury from the monopolar instrument. Surg Endosc 30, 4776-4784. https://doi.org/10.1007/s00464-016-4807-z.

31. Feldman LS, Brunt LM, Fuchshuber P, Jones DB, Jones SB, Mischna J, Munro MG, Rozner MA, Schwaitzberg SD, Committee SF (2013), Rationale for the fundamental use of surgical energy (FUSE) curriculum assessment: focus on safety. Surg Endosc 27, 4054-4059. https://doi.org/10.1007/ s00464-013-3059-4.

32. Meeuwsen FC, Guedon ACP, Arkenbout EA, van der Elst M, Dankelman J, van den Dobbelsteen JJ (2017), The art of electrosurgery: trainees and experts. Surg Innov 24, 373-378. https://doi.org/10.1177/1553350617705207.

33. Jones DB, Brunt LM, Feldman LS, Mikami DJ, Robinson TN, Jones SB (2015), Safe energy use in the operating room. Curr Probl Surg 52, 447-468. https://doi.org/10.1067/j. cpsurg.2015.08.004.

34. Govekar HR, Robinson TN, Stiegmann GV, McGreevy FT (2011), Residual heat of laparoscopic energy devices: how long must the surgeon wait to touch additional tissue? Surg Endosc 25, 3499-3502. https://doi.org/10.1007/s00464-0111742-x.

35. Nilsson L, Risberg MB, Montgomery A, Sjodahl R, Schildmeijer K, Rutberg H (2016), Preventable adverse events in surgical care in Sweden: a nationwide review of patient notes. Medicine (Baltimore) 95, e3047. https://doi.org/10.1097/ MD.0000000000003047.

36. Maier-Hein L, Vedula SS, Speidel S, Navab N, Kikinis R, Park A, Eisenmann M, Feussner H, Forestier G, Giannarou S, Hashizume M, Katic D, Kenngott H, Kranzfelder M, Malpani A, Marz K, Neumuth T, Padoy N, Pugh C, Schoch N, Stoyanov D, Taylor R, Wagner M, Hager GD, Jannin P
(2017), Surgical data science for next-generation interventions. Nat Biomed Eng 1, 691-696. https://doi.org/10.1038/ s41551-017-0132-7.

37. Buess G, Naruhn M, Motzung T, Mentges B, Becker HD (1991), Training program for minimally invasive surgery. Chirurg 62, 276-283.

38. Roberts KE, Bell RL, Duffy AJ (2006), Evolution of surgical skills training. World J Gastroenterol 12, 3219-3224. https://doi.org/10.3748/wjg.v12.i20.3219.

39. Aggarwal R, Grantcharov T, Moorthy K, Milland T, Papasavas P, Dosis A, Bello F, Darzi A (2007), An evaluation of the feasibility, validity, and reliability of laparoscopic skills assessment in the operating room. Ann Surg 245, 992-999. https://doi.org/10.1097/01.sla.0000262780.17950.e5.

40. Brown C, Abdelrahman T, Patel N, Thomas C, Pollitt MJ, Lewis WG (2017), Operative learning curve trajectory in a cohort of surgical trainees. Br J Surg 104, 1405-1411. https://doi.org/10.1002/bjs.10584.

41. Nickel F, Kowalewski KF, Rehberger F, Hendrie JD, Mayer BF, Kenngott HG, Bintintan V, Linke GR, Fischer L, Muller-Stich BP (2017), Face validity of the pulsatile organ perfusion trainer for laparoscopic cholecystectomy. Surg Endosc 31, 714-722. https://doi.org/10.1007/s00464-0165025-4.

42. Liu W, Zheng X, Wu R, Jin Y, Kong S, Li J, Lu J, Yang H, $\mathrm{Xu} \mathrm{X}$, Lv Y, Zhang X (2018), Novel laparoscopic training system with continuously perfused ex-vivo porcine liver for hepatobiliary surgery. Surg Endosc 32, 743-750. https://doi. org/10.1007/s00464-017-5731-6.

43. Gallagher AG, Al-Akash M, Seymour NE, Satava RM (2009), An ergonomic analysis of the effects of camera rotation on laparoscopic performance. Surg Endosc 23, 26842691. https://doi.org/10.1007/s00464-008-0261-x.

44. Arikatla V, Horvath S, Fu Y, Cavuoto L, De S, Schwaitzberg S, Enquobahrie A (2019), Development and face validation of a virtual camera navigation task trainer. Surg Endosc 33, 1927-1937. https://doi.org/10.1007/s00464-018-6476-6.

45. Brackmann MW, Andreatta P, McLean K, Reynolds RK (2017), Development of a novel simulation model for assessment of laparoscopic camera navigation. Surg Endosc 31, 3033-3039. https://doi.org/10.1007/s00464-016-5323-x.

46. Huber T, Paschold M, Schneble F, Poplawski A, Huettl F, Watzka F, Lang H, Kneist W (2018), Structured assessment of laparoscopic camera navigation skills: the SALAS score. Surg Endosc 32, 4980-4984. https://doi.org/10.1007/s00464018-6260-7.

47. Pucher PH, Brunt LM, Fanelli RD, Asbun HJ, Aggarwal R (2015), SAGES expert Delphi consensus: critical factors for safe surgical practice in laparoscopic cholecystectomy. Surg Endosc 29, 3074-3085. https://doi.org/10.1007/s00464-0154079-z.

48. Strasberg SM, Hertl M, Soper NJ (1995), An analysis of the problem of biliary injury during laparoscopic cholecystectomy. J Am Coll Surg 180, 101-125.

49. Palter VN, Orzech N, Reznick RK, Grantcharov TP (2013), Validation of a structured training and assessment curriculum for technical skill acquisition in minimally invasive surgery: a randomized controlled trial. Ann Surg 257, 224230. https://doi.org/10.1097/SLA.0b013e31827051cd.

50. Shaharan S, Neary P (2014), Evaluation of surgical training in the era of simulation. World J Gastrointest Endosc 6, 436447. https://doi.org/10.4253/wjge.v6.i9.436.

51. Vanderbilt AA, Grover AC, Pastis NJ, Feldman M, Granados DD, Murithi LK, Mainous AG 3rd (2014), Randomized controlled trials: a systematic review of laparoscopic surgery and simulation-based training. Glob J Health Sci 7, 310-327. https://doi.org/10.5539/gjhs.v7n2p310. 
52. Barrett M, Asbun HJ, Chien HL, Brunt LM, Telem DA (2018), Bile duct injury and morbidity following cholecystectomy: a need for improvement. Surg Endosc 32, 16831688. https://doi.org/10.1007/s00464-017-5847-8.

53. Nagendran M, Gurusamy KS, Aggarwal R, Loizidou M, Davidson BR (2013), Virtual reality training for surgical trainees in laparoscopic surgery. Cochrane Database Syst Rev 8, CD006575. https://doi.org/10.1002/14651858. CD006575.pub3.

54. Zendejas B, Brydges R, Hamstra SJ, Cook DA (2013), State of the evidence on simulation-based training for laparoscopic surgery: a systematic review. Ann Surg 257, 586-593. https://doi.org/10.1097/SLA.0b013e318288c40b.

55. Gurusamy KS, Nagendran M, Toon CD, Davidson BR (2014), Laparoscopic surgical box model training for surgical trainees with limited prior laparoscopic experience. Cochrane Database Syst Rev 3, CD010478. https://doi.org/10.1002/ 14651858.CD010478.pub2.

56. Nagendran M, Toon CD, Davidson BR, Gurusamy KS (2014), Laparoscopic surgical box model training for surgical trainees with no prior laparoscopic experience. Cochrane Database Syst Rev 1, CD010479. https://doi.org/10.1002/ 14651858.CD010479.pub2.

57. Guedes HG, Camara Costa Ferreira ZM, de Sousa Ribeiro, Leao L, Souza Montero EF, Otoch JP, Artifon ELA (2019), Virtual reality simulator versus box-trainer to teach minimally invasive procedures: a meta-analysis. Int J Surg 61, 6068. https://doi.org/10.1016/j.ijsu.2018.12.001.

58. Vedula SS, Ishii M, Hager GD (2017), Objective assessment of surgical technical skill and competency in the operating room. Annu Rev Biomed Eng 19, 301-325. https://doi.org/ 10.1146/annurev-bioeng-071516-044435.

59. Funke I, Mees ST, Weitz J, Speidel S (2019), Video-based surgical skill assessment using 3D convolutional neural networks. Int J Comput Assist Radiol Surg 14, 1217-1225. https://doi.org/10.1007/s11548-019-01995-1.

60. Eisawi A, Aung M, Canelo R (2020), A novel dual-phase activation-dependent foot-switch mechanism for surgical energy devices as an asset in early surgical training: a proof of concept study. Surg Innov 27, 54-59. https://doi.org/ $10.1177 / 1553350619870030$.

61. Diana M, Soler L, Agnus V, D'Urso A, Vix M, Dallemagne B, Faucher V, Roy C, Mutter D, Marescaux J, Pessaux P (2017), Prospective evaluation of precision multimodal gallbladder surgery navigation: virtual reality, near-infrared fluorescence, and X-ray-based Intraoperative cholangiography. Ann Surg 266, 890-897. https://doi.org/10.1097/ SLA.0000000000002400.

62. van Duren BH, van Boxel GI, Hart A, Newton N (2016), A novel safety mechanism to reduce the risk of inadvertent electrosurgical injury. J Med Eng Technol 40, 239-244. https://doi.org/10.3109/03091902.2016.1162214.

63. Barbash GI, Glied SA (2010), New technology and health care costs-the case of robot-assisted surgery. N Engl J Med 363, 701-704. https://doi.org/10.1056/NEJMp1006602.

64. Bodenstedt S, Wagner M, Mundermann L, Kenngott H, MullerStich B, Breucha M, Mees ST, Weitz J, Speidel S (2019), Prediction of laparoscopic procedure duration using unlabeled, multimodal sensor data. Int J Comput Assist Radiol Surg 14, 1089-1095. https://doi.org/10.1007/s11548-019-01966-6.

Cite this article as: Rolinger J, Model N, Jansen K, Knöll M, Beyersdorffer P, et al. 2022. Quantification of electrosurgery-related critical events during laparoscopic cholecystectomy - a prospective experimental study among surgical novices. 4 open, $\mathbf{5}, 4$. 